Psychiatric Bulletin (2000), 24, 241-242

TIM AMOS AND JENNY SHAW

\title{
Reviewing serious incidents
}

Rose (2000, this issue) describes an interesting method of reviewing local serious incidents. The model appears to be a good one for other services to follow and adapt to local needs. The paper raises issues about the role of local reviews and what they can achieve in comparison with other forms of monitoring the deaths of patients, particularly national clinical surveys such as the National Confidential Inquiry into Suicide and Homicide by People with Mental Illness (Appleby et al, 1999).

There are several strengths in the local review process. First, a detailed peer review can take place. The Oxford reviews involved a wide range of professionals, including staff working outside of the health field, allowing points of view to be expressed by a variety of personnel, many of whom were not directly involved in the individual cases. This is important, as one of the major criticisms from many of the individual homicide inquiries is the lack of inter-agency communication and cooperation (Ritchie et al, 1994). Regular meetings of professionals are likely to improve links between agencies at a local level. Second, the findings of the review can be directly related to specific local services and the local environment. For example, sites where suicides commonly occur are more likely to be identified if several agencies, including the police, are involved. Third, findings from the local review cases can also be compared with the national pattern to highlight any differences. Local reviews should not aim to find risk factors for suicide which are already well established, such as male gender, unemployment and living alone. Instead, local audits aim to spot local patterns or high-risk groups which large national samples might obscure.

However, there are also limitations in local reviews. Numbers of incidents in any local service will be small. The average population size of a health authority is 500000 and thus there will be approximately 50 suicides a year in any one health authority. Using data obtained by the National Confidential Inquiry (Appleby et al, 1999), it can be estimated that in each district, annually, there will be 12 (i.e. $24 \%$ of 50 ) suicides in contact with mental health services. Of these, only two will be in-patient suicides and a further three will be suicides committed by individuals who have been discharged from hospital within the previous three months. The equivalent numbers for individual hospitals will be even smaller. One way of increasing numbers is to include all serious incidents and not just those which result in death, as the Oxford team has done, but different types of incidents may not fit easily together. For example, suicides and serious suicide attempts are probably closely related and have some links with external manifestations of violence, such as assaults, but they are not the same. Events such as cardiac arrests during electroconvulsive therapy may have even less in common with suicides. However, investigation of any serious event may well reveal systematic errors in the service, such as poor supervision of junior staff, and may therefore be of benefit (Oyebode, 1999).

Local services may be unaware of some suicides, particularly where individuals have not been in recent contact with services. Some of these may be exactly the cases in which a proper local review would be useful, and on which guidelines on assertive follow-up could be based.

Local lessons need to be of use locally. One of the strengths of the Oxford experience is that there seems to have been a large number of changes to the local services as a result of case review. Training and staff needs, and access to the means of self-injury have all figured highly. A number of protocols and procedures have been developed, updated and incorporated into training. It is essential that the results of the review process are integrated into clinical services so that the recommendations make a difference to subsequent practice and the clinical care of patients. The dissemination of, and the action following, recommendations should be monitored.

Learning from experience has become a priority in the modern NHS. One function of clinical governance is to monitor the mechanisms for addressing serious incidents (NHS Executive, 1999). The role of the newlyestablished Commission of Health Improvement is to check that these mechanisms are working properly (Department of Health, 1998). There are also three high-level committees considering 'untoward incidents'. The House of Commons Health Select Committee (1999) has published a report which suggests that setting-up of a national database of 'adverse clinical incidents' in the NHS. The Committee recommends that local communities should be involved in monitoring and maintaining standards. A second high-level committee, 
an

editorial
Health Advisory 2000, has been commissioned by the Department of Health to suggest a new process of inquiring into adverse incidents in mental health services. If its report is accepted, its proposal will replace the requirements of the Department of Health (1994) circular that made it mandatory to hold an independent inquiry after every homicide by someone with previous contact with mental health services. The third committee, chaired by Professor Liam Donaldson, Chief Medical Officer, is due to make recommendations on how the NHS as a whole can investigate and respond to adverse incidents. In addition, the recent National Service Framework for Mental Health set standards, with the aim of preventing suicide, which emphasise the role of the local suicide audit in learning lessons and taking action as necessary (Department of Health, 1999). Thus, the description of the Oxford model is timely - as all services will have to develop an equivalent that can stand up to professional, political and public scrutiny.

\section{References}

APPLEBY, L., SHAW, J, AMOS, T., et al (1999) Safer Services. Report of the National Confidential Inquiry into Suicide and Homicide by People with Mental IIIness. London: Department of Health.

DEPARTMENT OF HEALTH (1994) Guidance on the Discharge of Mentally Disordered People and their Continuing Care in the Community. Circular (HSG (94)27). London: NHS Executive.

— (1998) A First Class Service. Quality in the New NHS. London: Department of Health.

- (1999) A National Service

Framework for Mental Health: Modern Standards and Service Models. London: Department of Health.

HOUSE OF COMMONS HEALTH SELECT COMMITTEE (1999) Procedures Related to Adverse Clinical Incidents and Outcomes in Medical Care. London: The Stationery Office.

NHS EXECUTIVE (1999) Clinical

Governance: Quality in the New NHS (HSC 1999/065). London: NHS

Executive.

OYEBODE, F. (1999) Invited commentary: Anatomy of risk Psychiatric Bulletin, 23, 652-653.

RITCHIE, J., DICK, D. \& LINGHAM, R. (1994) The Report of the Inquiry into the Care and Treatment of Christopher Clunis. London: HMSO.

ROSE, N. (2000) Six years'experience in Oxford. Review of serious incidents. Psychiatric Bulletin, 24, 243-246.

*Tim Amos Clinical Research Fellow, Jenny Shaw Assistant Director, National Confidential Inquiry into Suicide and Homicide by People with Mental IIness, PO Box 86, Manchester M20 2EF 